\title{
The SENS algorithm-a new nutrient profiling system for food labelling in Europe
}

\author{
Nicole Darmon ${ }^{1} \cdot$ Juliette Sondey $^{2} \cdot$ Véronique Azaïs-Braesco $^{3} \cdot$ Matthieu Maillot $\mathbb{B}^{2}$
}

Received: 27 October 2016 / Revised: 4 September 2017 / Accepted: 8 September 2017 / Published online: 20 December 2017

(c) The Author(s) 2018. This article is published with open access

\begin{abstract}
Background/objectives In response to the European regulation on nutrition and health claims, France proposed in 2008 the SAIN,LIM profiling system that classifies foods into four classes based on a nutrient density score called 'SAIN', a score of nutrients to limit called 'LIM', and one primary threshold on each score. We present here the SENS algorithm, a new nutrient profiling system adapted from the SAIN,LIM to be operational for simplified nutrition labelling in line with the European regulation on food information to consumers.

Subjects/methods The main changes made to SAIN,LIM to get SENS were to introduce food categories and subcategories ('Beverages', 'Added Fats' and 'Other Solid Foods' sub-categorised into 'cereals', 'cheese', 'other dairy products', 'eggs', 'fish' and 'others'), reduce the number of nutrients, introduce category-specific nutrients and category-specific weighting for some nutrients, replace French recommendations with European reference intakes, and add secondary thresholds. Each food and non-alcoholic beverage from the 2013-CIQUAL French composition database $(n=1065)$ was assigned one SENS class. Distribution of foods according to the four SENS classes was described by food groups $(n=26)$.

Results The SENS classification was consistent with the recommendations to consume large amounts of whole grains, vegetables and fruits, and moderate intake of fats, sugars, meats, caloric beverages and salt. For most groups (19/26), foods were distributed across at least three SENS classes.

Conclusions The SENS is a nutrition-sensitive system that discriminates foods between and within food categories. It preserves the strengths of the initial SAIN,LIM while making it operational for simplified nutrition labelling in Europe.
\end{abstract}

\section{Introduction}

European Regulation No. 1169/2011 on the provision of food information to consumers frame the rules for food and nutrition labelling in Europe [1]. A nutrition declaration, which content and format are precisely defined by the regulation, is now mandatory for most pre-packed foods in Europe. To facilitate consumer understanding of nutrition information, the regulation also allows additional forms of expression and presentation such as front-of-pack logos.

Nicole Darmon

Nicole.darmon@inra.fr

1 MOISA, INRA, CIHEAM-IAMM, CIRAD, Montpellier SupAgro, Univ Montpellier, Montpellier, France

2 MS-Nutrition, Marseille, France

3 VAB-Nutrition, Clermont-Ferrand, France
Simplified nutrition labelling on foods requires a validated nutrient profiling system that is able to rank foods according to their nutritional composition, as defined by the World Health Organization (WHO) [2].

Several nutrient profiling systems have been proposed worldwide to judge the nutritional quality of a particular food based on its nutrient content [3]. Most systems were developed for the purpose of food certification, i.e. identifying foods able to be advertised (e.g. the FSA-Ofcom model in the United Kingdom [4]), eligible to health claims (e.g. The Nutrient Profiling Scoring Criterion (NPSC) score in Australia and New Zealand [5]) or identifying foods able to carry a positive front-of-pack logo such as the Nordic Keyhole [6], the Finnish Heart symbol [7] and the Choices International logo [8]. While the above systems translate into an aggregated dichotomous evaluation (healthy/less healthy; certified/not certified), other nutrient profiling systems underlying front-of-pack logos provide a differential evaluation of specific nutrients. The UK Traffic Light 
system, for example, provides a separate evaluation of energy, total fat, saturated fat, total sugars and salt, with green, amber and red colours indicating low, medium and high content of each nutrient [9].

Which nutrient profiling system should be used to implement simplified nutrition labelling is not stipulated by regulation No. 1169/2011 on the provision of food information to consumers, but some requirements must be met [1]. One of those requirements is that additional forms must be based either on the harmonised reference intakes set out in the regulation-the EU reference intakes (EU-RIs)—or in their absence, on generally accepted scientific advice on intakes for energy or nutrients. Among the above cited systems, the UK Traffic Light is the only one to explicitly integrate EU-RIs in its calculation [9]. But there could be some concern with multiple evaluation of individual nutrients as consumers may put too strong reliance on one piece of nutritional information when making decisions, and concerns can also be raised with dichotomous evaluation that consumers may oversimplify the relative healthiness of foods by categorising them into either good or bad foods [3].

Another form of evaluation is the overall rating of the nutritional quality, such as that provided by the Health Star Rating system, a front-of-pack labelling system that assigns $1 / 2$ star to 5 stars [10] or by the ' $5 \mathrm{C}$ ' [11], which assigns one of five colours from light green to red, according to the overall quality of the packaged food. Such overall rating of the nutritional quality of foods may provide a more intuitive understanding, although it is generally acknowledged that no system or symbol is perfect [3, 12].

The SAIN,LIM system-which classifies foods into four classes based on a threshold put on each of two scores, a nutrient density score called 'SAIN' and a score of nutrients to limit, called 'LIM' - was developed by the French Food Safety Agency in 2008 [13] in response to the EU regulation on nutrition and health claims [14], but it presents weaknesses to be used for simplified labelling in accordance with the European Regulation No. 1169/2011 on the provision of food information to consumers. Indeed, it is based on French rather than EU recommendations, its four classes allow large edge-effects, and its positive score would gain from requiring fewer nutrients and being more categoryspecific. Nevertheless, the SAIN,LIM does possess valuable strengths, such as being based on official recommendations and not compensating positive and negative scores, which makes it better able to discriminate foods according to nutrient density even when they have similar content of nutrients to limit, i.e. the same LIM score.

In line with WHO guidelines [15] and with the EU regulation [1] supporting multi-stakeholder consultation, a group of scientific experts, teamed up with members of French food retailers and industries, have developed and 


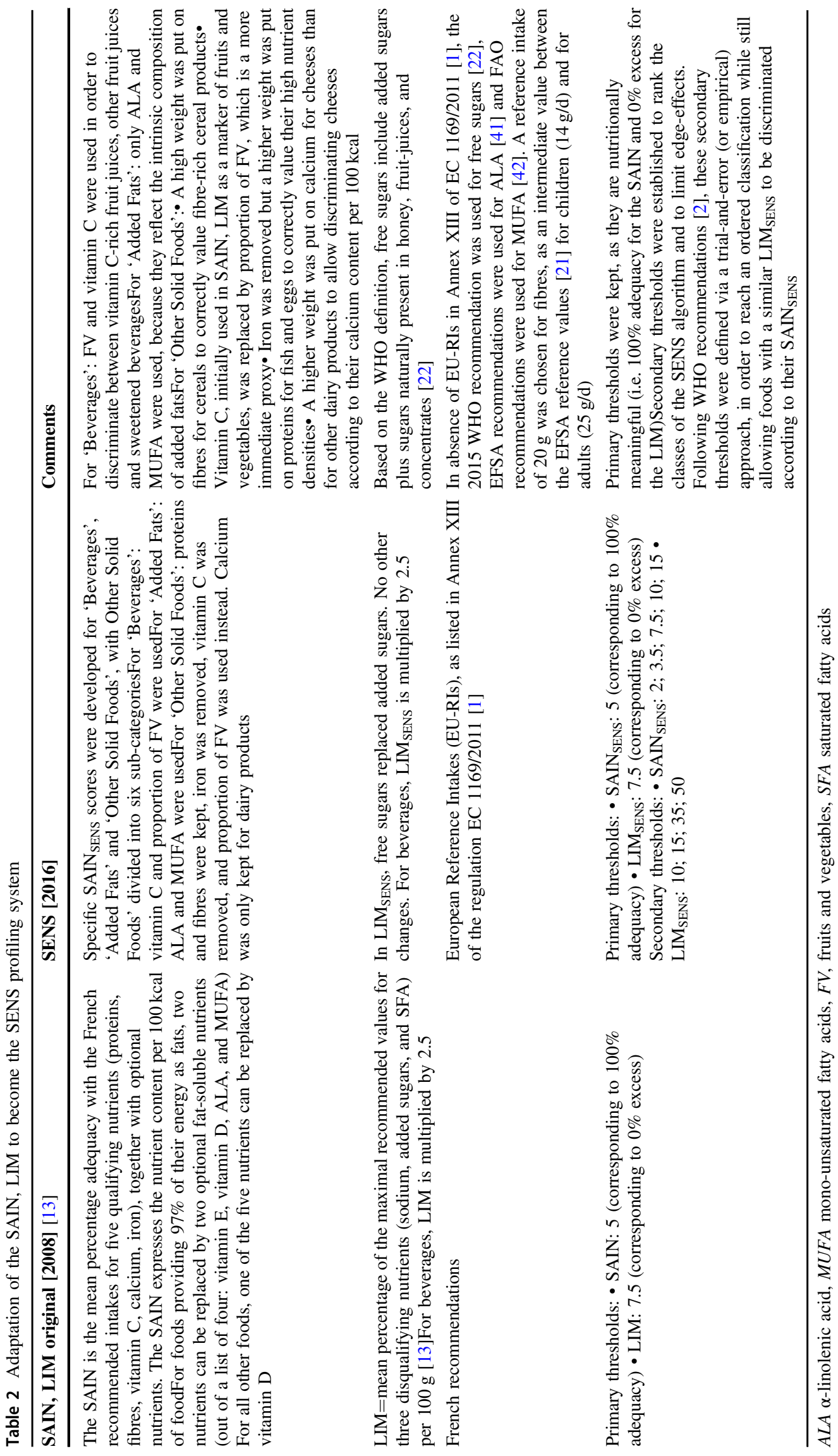




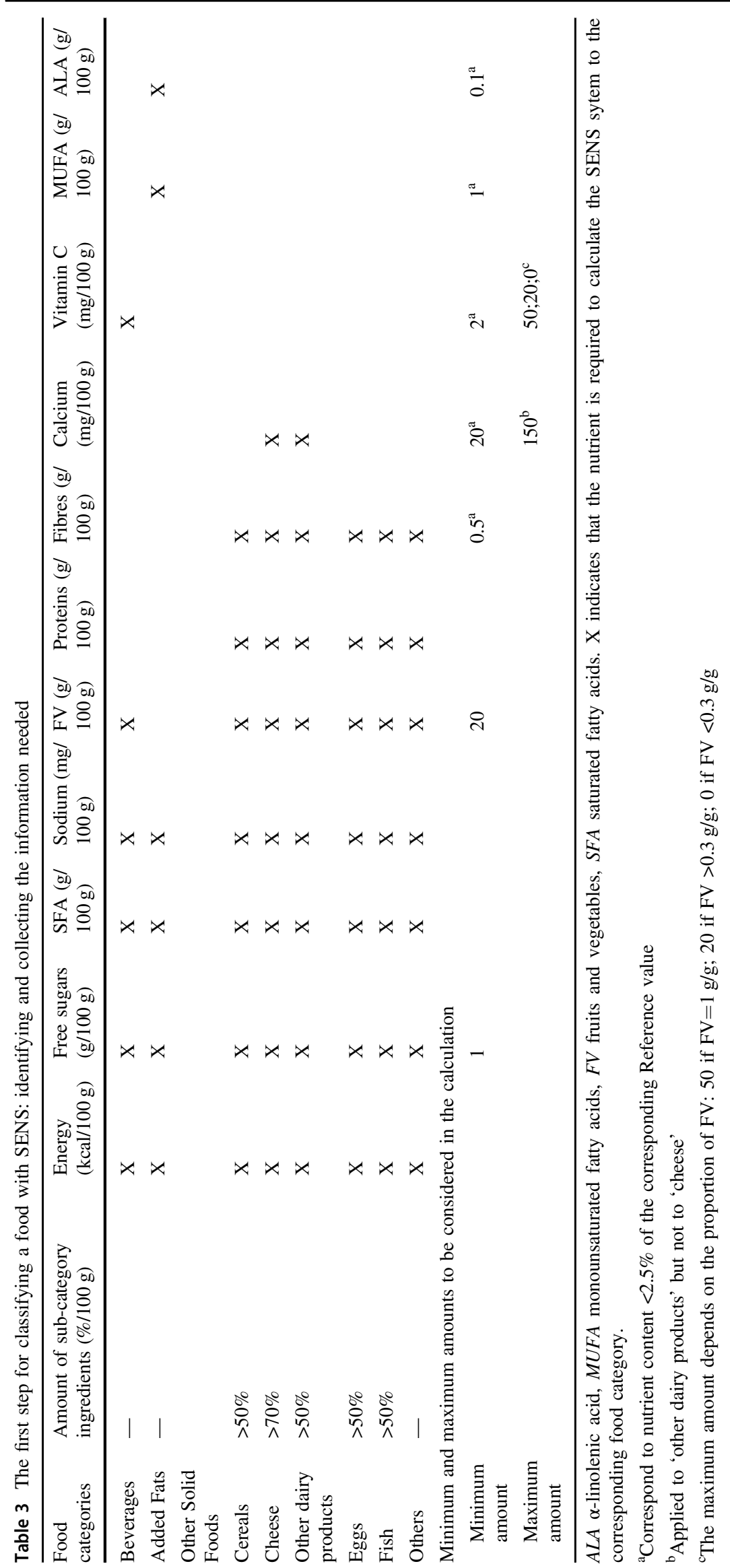




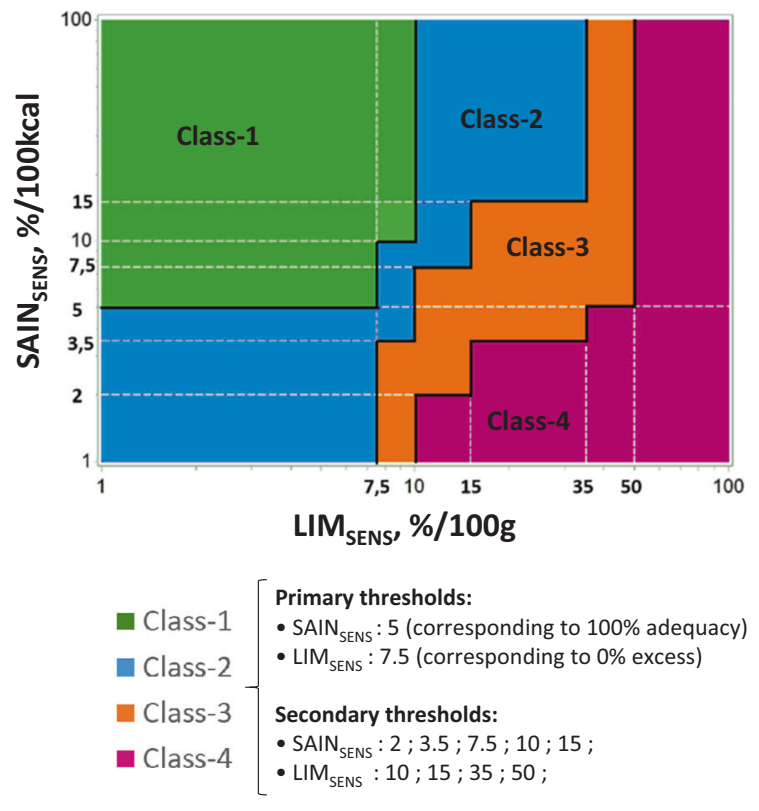

Fig. 1 The third step for classifying a food with SENS: allocating foods to one of the four SENS classes according to the thresholds applied to the scores (two exceptions to the general ranking were introduced. First, non-water beverages that the algorithm had allocated to Class 1 were systematically downgraded to Class 2 . Second, in the 'Other solid foods' category, foods exceeding $400 \mathrm{kcal} / 100 \mathrm{~g}$ allocated to Class 1 were systematically downgraded to Class 2, or from Class 2 to Class 3, and foods with an ED $>500 \mathrm{kcal} / 100 \mathrm{~g}$ and a sodium (Na) content $>200 \mathrm{mg} / 100 \mathrm{~g}$ allocated to Class 3 were downgraded to Class 4)

tested the algorithm of the SENS (Système d'Etiquetage Nutritionnel Simplifié [simplified nutrition labelling system]) on the principles of integrity and transparency. The aim of the present article was to describe the SENS algorithm, a new nutrient profiling system to be used for food labelling in Europe.

\section{Materials and methods}

\section{From the SAIN,LIM system to the SENS algorithm}

WHO advocates the use of a systematic, transparent and logical step-by-step process [2], which was carefully followed to develop the SENS (Table 1). One of the initial steps was to decide whether or not to use an existing system. The choice made was to adapt the existing SAIN,LIM system, which classifies foods based on a qualifyingnutrients score, the SAIN (score for the nutritional adequacy of individual foods) and a disqualifying-nutrients score, the LIM (score of nutrients to limit) [13]. In order to address the limitations of the SAIN,LIM for simplified labelling in Europe, several adaptations were made (Table 2) to reduce the number of nutrients, take into account the specificity of food categories, integrate EU reference intakes (EU-RIs) and better order the four classes. These adaptations were introduced progressively, following an iterative process described in detail in a dedicated report [16].

As for the SAIN,LIM system [17], the choice of nutrients to be included in the SENS reflected a balance between the need to include (i) elements of public health importance, in particular fruits and vegetables (FV), saturated fatty acids, sodium, dietary fibre and unsaturated fatty acids, intakes of which generally do not comply with recommendations in EU Member States [18], (ii) nutrients that are markers of the presence of other essential nutrients (proteins were initially included in the SAIN,LIM because they were found to be correlated with vitamins B1, B2, B3, B5, B6, B12, potassium, magnesium, iodine, selenium and zinc in foods [17]) and (iii) nutrient markers of key food categories that are subject to dietary recommendations. Thus, to better reflect the nutritional value of some categories and sub-categories, category-specific nutrients and category-specific weighting for some nutrients were introduced. Vitamin $\mathrm{C}$ was used as a category-specific nutrient for 'Beverages' in order to discriminate between vitamin $\mathrm{C}$-rich fruit juices and other fruit-based beverages. FV content was also used in 'Beverages' in order to distinguish between juices and sweetened beverages (i.e. empty calories). Alpha-linolenic acid (ALA) and monounsaturated fatty acids (MUFA) were used as category-specific nutrients for 'Added Fats' because they reflect intrinsic composition of added fats. Calcium was used as a category-specific nutrient for 'Cheese' and 'Other dairy products' because they are the main calcium providers in the European diet. A higher weight was put for calcium in cheese than in other dairy products, because this allowed discriminating cheeses according to their calcium content per $100 \mathrm{kcal}$.

For some sub-categories, the category-specific nutrient was already included in the general SAIN SENS $_{2}$ equation (i.e. fibres for 'Cereals'; proteins for 'Eggs' and for 'Fish') and a weighting factor was introduced to better reflect the nutritional value of the sub-category. Thus, a higher weight was put on fibres for the 'Cereals' subcategory in order to correctly value fibres-rich cereal products. A higher weight was put on proteins for the 'Eggs' and 'Fish' sub-categories to correctly valorise their high nutrient densities.

\section{The SENS nutrient profiling system}

The SENS algorithm allocates a class to a food according to the value of a qualifying score, the SAIN $\mathrm{SENS}_{\mathrm{S}}$, and a dis-

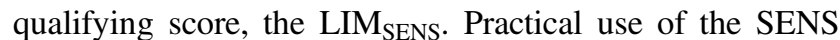
algorithm requires three main steps: (i) collecting food composition information (ingredients and nutrients) and categorising the selected food, then (ii) estimating the 


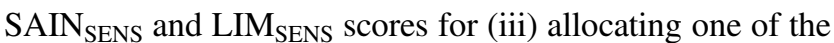
four SENS classes according to scores and thresholds.

\section{Collecting food composition information (ingredients and nutrients) and categorising the selected food}

A food selected to be profiled by the SENS algorithm has to be categorised within either 'Beverages', 'Added Fats' or 'Other Solid Foods'(Table 3). 'Beverages' refers to water and all other beverages (soups, milk and plant-based milk alternatives excluded). 'Added Fats' refers to what the French food-based dietary guidelines define as 'visible' fats, i.e. fats added by oneself [19] such as oil, butter, cream, mayonnaise or vinaigrette.

All other foods are identified as 'Other Solid Foods', which is then sub-categorised into either 'cereals', 'cheese', 'other dairy products', 'eggs' or 'fish' when it contains more than $50 \mathrm{~g}$ of that sub-category ingredient for $100 \mathrm{~g}$ (or more than $70 \mathrm{~g} / 100 \mathrm{~g}$ for the 'cheese'). If this condition is not met, the food is sub-categorised as 'others'. In practice, category-specific nutrients were needed only for 'Beverages' (i.e. vitamin C) and 'Added Fats' (i.e. ALA and MUFA) categories and for the 'Cheese' and 'Other dairy products' (i.e. calcium) sub-categories. For some nutrients or components, minimum and/or maximum amounts were established. Minimum amounts aim at avoiding counting marginal quantities while maximum amounts are intended to avoid encouraging non-relevant practices of excessive nutrient fortification. For Beverages, the amount of FV is used to control the weight given to vitamin $\mathrm{C}$ in the

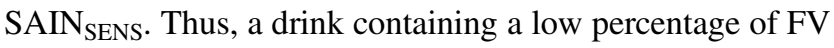
cannot be upgraded by a vitamin $\mathrm{C}$ addition.

As an ingredient, FV count raw or only slightly processed (cooked, peeled, sliced, tinned frozen and puree) fruit and vegetables. Components extracted from fruits and vegetables (e.g. concentrated fruit juice sugar, powders) are not included. Tubers (potatoes), seeds (nuts, almonds, etc), dry or dried fruit, legumes, maize (which is excluded as a cereal but counted among vegetables as sweetcorn) are excluded from the calculation. In processed products, the content of $\mathrm{FV}$ has been estimated using disaggregated recipes (every time it was possible) and/or the percentage of different FV which should be mentioned on the ingredient list when the products highlights its FV content.

\section{Estimating the SAIN ${ }_{\text {SENS }}$ and LIM $_{\text {SENS }}$ scores}

Reference amounts used for the SAIN,LIM system (i.e. 100 kcal for the SAIN and $100 \mathrm{~g}$ for the LIM) were kept for the SENS, because it was previously shown that models based on $100 \mathrm{kcal}$ are preferable for positive subscores and models based on $100 \mathrm{~g}$ food are preferable for negative subscores [20] (Table 4).
SAIN $_{\text {SENS }}$ score is the mean percentage adequacy with recommended intakes of qualifying nutrients, expressed per $100 \mathrm{kcal}$ and of $\mathrm{FV}$, in $\mathrm{g}$ per $\mathrm{g}$.

Specific SAIN $_{\text {SENS }}$ scores are applied for 'Beverages', 'Added Fats' and 'Other Solid Foods'.

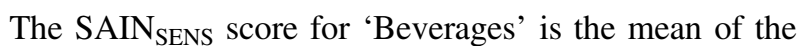
proportion of $\mathrm{FV}$ and the percentage of the EU-RI for Vitamin C.

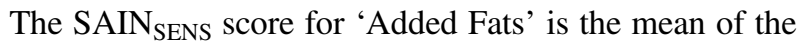
percentages of intakes recommended by the Food and Agriculture Organization of the United Nations (FAO) for ALA and the European Food Safety Agency (EFSA) for MUFA.

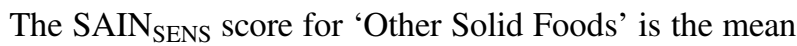
of the proportion of $\mathrm{FV}$, percentage of the EU-RIs for proteins and percentage of a reference intake for fibres-set at $20 \mathrm{~g}$ in absence of EU-RI in Annex XIII of Regulation EC 1169/2011 [1]. Regarding fibres, a reference intake of $20 \mathrm{~g}$ was chosen, as an intermediate value between the EFSA reference values [21] for children $(14 \mathrm{~g} / \mathrm{d})$ and for adults $(25 \mathrm{~g} / \mathrm{d})$. A value of $20 \mathrm{~g}$ was more able than a higher one to value fibres-rich foods because references values for qualifying nutrients are situated at the numerator in (SAIN and) SAIN $_{\text {SENS }}$ score(s), so that the lower the reference value the higher the score. The different sub-categories were treated as follows: calcium was added for 'cheese' and 'other dairy products', given a weighting factor of 2 and 1, respectively; a weighing factor of 2 was given to proteins for the 'eggs' and 'fish' sub-categories; a weighing factor of 3 was given to fibres for the 'cereals' sub-category.

LIM $_{\text {SENS }}$ score is the mean percentage of the maximal recommended values in $100 \mathrm{~g}$ of food of three disqualifying nutrients, i.e. sodium ( $2400 \mathrm{mg}$ ), saturated fatty acids (SFA) $(20 \mathrm{~g})$ and free sugars $(50 \mathrm{~g})$. Based on the WHO definition, free sugars include added sugars plus sugars naturally present in honey, fruit juices and concentrates [22]. The use of free sugars rather than total sugars as disqualifying nutrient was decided to avoid disadvantaging products with high nutrient density but naturally containing sugars (i.e. skimmed milk, fruit products). LIM SENS $_{\text {score is applied equally }}$ for all foods except 'Beverages' for which LIM $_{\text {SENS }}$ is multiplied by 2.5 , as in the original system.

\section{Allocating foods to one the four SENS classes according to thresholds applied to the scores}

The SENS algorithm ranks four classes based on primary and secondary thresholds applied to its two scores (Fig. 1). Primary thresholds previously defined for SAIN,LIM, i.e. 5 for SAIN and 7.5 for LIM [13] were kept for SENS because they are meaningful. Actually, for SAIN, a threshold of 5 for $100 \mathrm{kcal}$ corresponds to a nutritional adequacy of $100 \%$ for a reference daily energy intake of $2000 \mathrm{kcal}$. For LIM, a 
a) Energy density, kcal/100g

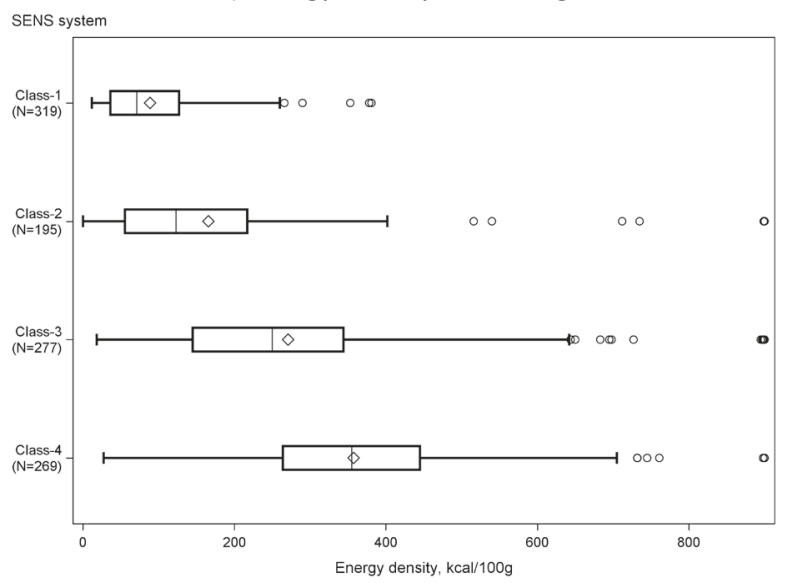

Fig. 2 Distribution (Boxplot represents first quartile; median, and third quartile; Diamonds represent the averages) of energy density (kcal/ $100 \mathrm{~g}$, a (median values are 71, 123, 250 and $355 \mathrm{kcal} / 100 \mathrm{~g}$ for Class 1, Class 2, Class 3 and Class 4, respectively)) and of nutrient density

threshold of 7.5 for $100 \mathrm{~g}$ corresponds to $0 \%$ excess in disqualifying nutrients for $1337 \mathrm{~g}$, the mean daily food intake observed in the French population, knowing that, in the most recently available dietary surveys in Europe, average diet weights are in the same order of magnitude [23]. Having one threshold on each score allows defining four classes but is not sufficient to order the four classes and to prevent from strong edge effects (small changes in the nutrient composition of a food could lead to leap over classes, even directly from Class 1 to Class 4). Therefore, to rank the four classes of the SENS algorithm and to limit edge-effects, secondary thresholds values of $10,15,35,40$ for $\mathrm{LIM}_{\mathrm{SENS}}$ and 2, 3.5, 7.5, 10, 15 for SAIN SENS $_{\text {were }}$ introduced. Following WHO recommendations [2], these secondary thresholds were defined based on a trial-and-error (or empirical) approach, in order to reach an ordered classification while still allowing foods with a similar LIM SENS $_{\text {S }}$ to be discriminated according to their $\mathrm{SAIN}_{\mathrm{SENS}}$ (and vice versa).

Foods can be positioned on a mapping with SAIN $_{\text {SENS }}$ and LIM $_{\text {SENS }}$ axes to determine their class. Water belongs ipso facto to Class 1 as its $\mathrm{SAIN}_{\mathrm{SENS}}$ is infinite (i.e. $0 \mathrm{kcal} /$ $100 \mathrm{~g}$ ) and its LIM SENS $_{\text {is zero. }}$

Two exceptions to the general ranking were introduced. Firstly, non-water beverages that the algorithm had allocated to Class 1 were systematically downgraded to Class 2 . Secondly, in the 'Other solid foods' category, foods exceeding $400 \mathrm{kcal} / 100 \mathrm{~g}$ allocated to Class 1 were systematically downgraded to Class 2 , or from Class 2 to Class 3 , and foods with an ED $>500 \mathrm{kcal} / 100 \mathrm{~g}$ and a sodium (Na) content $>200 \mathrm{mg} / 100 \mathrm{~g}$ allocated to Class 3 were downgraded to Class 4. Only three foods of the CIQUAL database were affected by the second exception. In fact, in b) Nutrient density score, $\% / 100 \mathrm{kcal}$

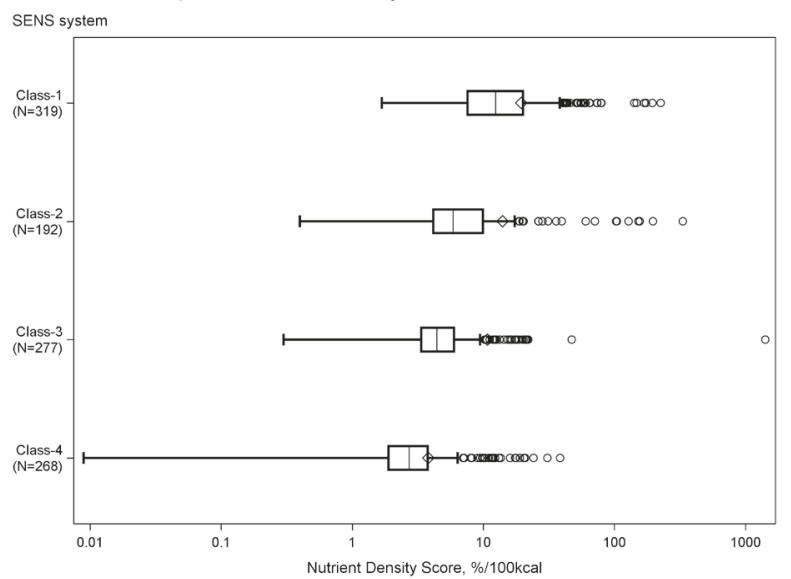

score (the nutrient density score was calculated as previously described [27]) $(\% / 100 \mathrm{kcal}, \mathbf{b}$ (median values are 12.4, 5.9, 4.4 and $2.7 \% / 100$ kcal for Class 1, Class 2, Class 3 and Class 4, respectively)) of CIQUAL foods (water excluded) by SENS class

the majority of cases, expressing SAIN SENS $_{\text {per }} 100 \mathrm{kcal}$ was sufficient to penalise foods with a high energy density, because of their automatically low SAIN SENS $_{\text {. However, }}$ rare cases remained where, despite a high energy density, some foods could access favourable SENS classes thanks to their relatively low LIM $_{\text {SENS }}$ (e.g. potato crisps with low amounts of sugar, SFA and limited amount of sodium). The second exception was therefore introduced to fully take into account global recommendation to reduce the intake of energy-dense foods to prevent excessive weight and obesity $[24,25]$.

\section{Application of the SENS algorithm to the French database and statistical analysis}

After removing duplicates, a final sample of 1065 foods and beverages (alcoholic beverages excluded) from the CIQUAL 2013 database distributed across 26 food groups (listed in Table 3) was included for analysis.

The amount of fibres (/100 g of foods) available in the CIQUAL 2013 database was estimated using the AOAC method. Some of the information required to estimate SENS class was missing from the CIQUAL food composition tables, which was completed with data on free sugars following the methodology published elsewhere [26]. For this study, standard recipes were provided by the French Agency for Food, Environmental and Occupational Health $\&$ Safety (limited access database), and were used to estimate the percentages of $\mathrm{FV}$, cheese, other dairy products, cereals, fish and eggs.

The 1065 CIQUAL foods were allocated to their SENS classes individually and by food group. In addition, the nutrient density of each food was estimated, using the 
Table 4 The second step for classifying a food with SENS: calculating the SAIN ${ }_{\text {SENS }}$ and LIM $_{\text {SENS }}$ scores

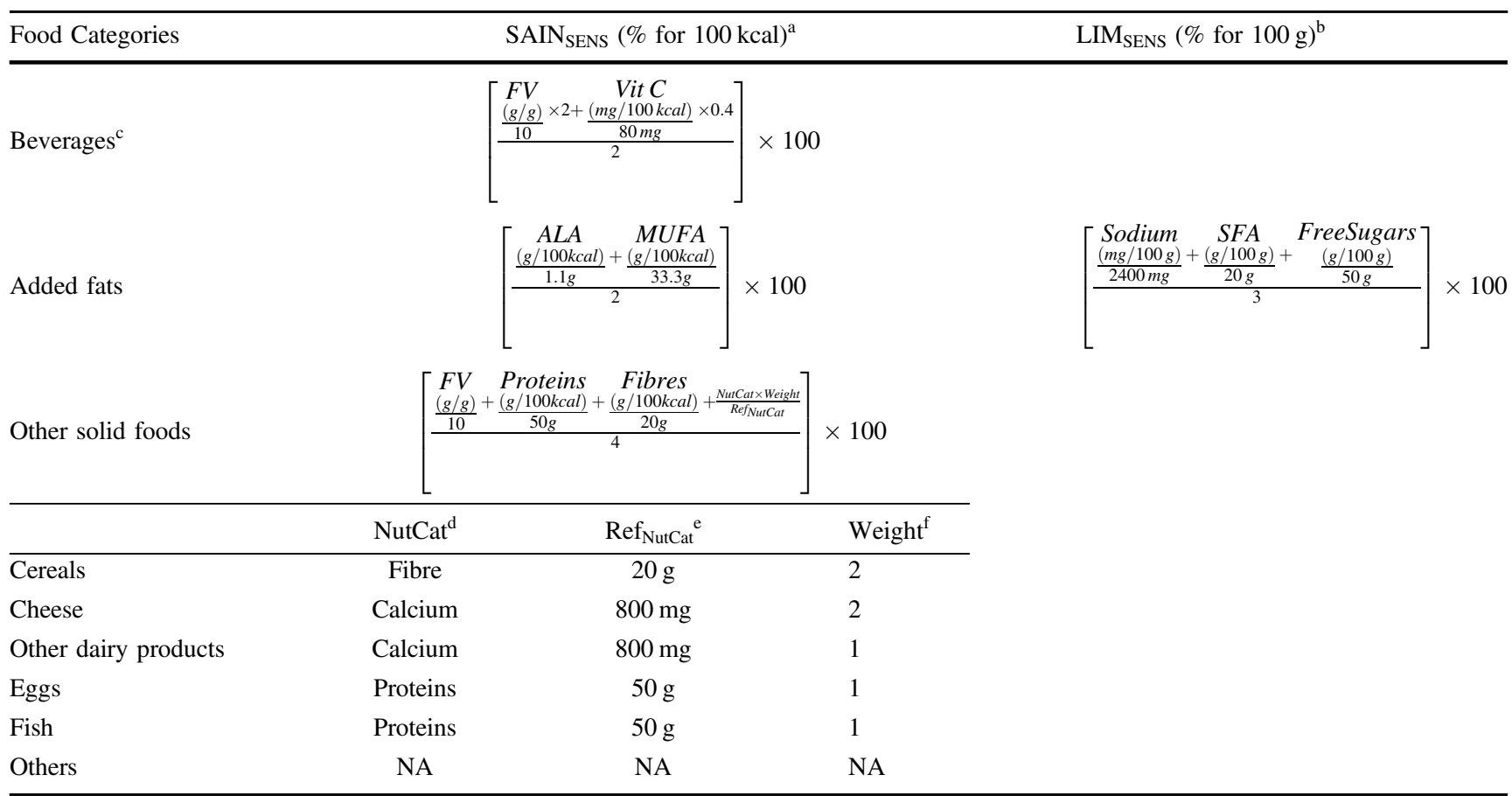

ALA $\alpha$-linolenic acid, MUFA monounsaturated fatty acids, $F V$ fruits and vegetables, Vit $C$ Vitamin $\mathrm{C}$, SFA saturated fatty acids

${ }^{a}$ Reference values correspond to the EU reference intakes (EU-RIs) for vitamin C, proteins and calcium [1], to the EFSA and FAO recommendations for ALA [41] and MUFA [42], and an intermediary value was set for fibres between EFSA values for children and adults [21]. For recommendations expressed in \% energy intake (ALA and MUFA), $2000 \mathrm{kcal}$ was used as the reference for daily energy intake

${ }^{b}$ Reference values correspond to the EU-RIs for sodium and SFA [1] and to the 2015 WHO recommendation for free sugars [22]. For recommendations expressed in \% energy intake (SFA, free sugars), $2000 \mathrm{kcal}$ was used as the reference for daily energy intake

'For 'Beverages', LIM ${ }_{\text {SENS }}$ is multiplied by 2.5

${ }^{\mathrm{d}}$ NutCat is the (sub)category-specific nutrient

${ }^{\mathrm{e}} \mathrm{Ref}_{\mathrm{NutCat}}$ is the reference value for NutCat

${ }^{\mathrm{f}}$ Weights give greater importance to some nutrients in the calculation

previously published nutrient density score (NDS), calculated as the mean percentage of adequacy for 16 positive nutrients in $100 \mathrm{kcal}$ of food [27]. Then, distributions of the NDS (in \% adequacy $/ 100 \mathrm{kcal}$ ) and of the energy density (ED, in $\mathrm{kcal} / 100 \mathrm{~g}$ ) of the foods were analysed across SENS classes and were compared using the non-parametric Kruskal-Wallis test.

\section{Results}

\section{Distribution of food groups by SENS classes}

Table 5 presents the distribution of CIQUAL foods (total $n$ $=1065$ ) across the four SENS classes for the 26 food groups, ranked by decreasing number of classes covered. The SENS algorithm classified $30.4 \%$ of CIQUAL foods in
Class 1, 18.3\% in Class 2, 26.0\% in Class 3 and 25.3\% in Class 4. Most food groups were spread across several classes: 10 groups were distributed in all four classes, 9 in three classes and 4 in two classes (Table 5). Only the beverages 'water', 'tea, coffee' and 'diet-sweetened beverages' were exclusively allocated to one class only.

Overall, the SENS algorithm attributed higher nutritional profiles (i.e. higher proportions of Class 1 and/or Class 2) to the groups termed 'fish', 'unrefined starches', 'vegetables, raw and cooked', 'fruits (fresh and processed)', 'tofu and soya-based products', 'fruit-juices', 'milk', 'yoghurt', 'tea, coffee', and 'diet-sweetened beverages'.

Strong trends appeared for some food groups: $93.2 \%$ of 'vegetables, raw and cooked' and around 70-75\% of 'fish', 'milk' and 'fruits' were classified in Class 1, and $86 \%$ of 'tofu/soya-based products' were classified in Class 2. Some food groups were distributed mainly 
Table 5 Distribution of CIQUAL foods (total $n=1065)$ and food groups $(n=26)$ across the four SENS classes

\begin{tabular}{|c|c|c|c|c|c|c|c|c|c|}
\hline \multirow{2}{*}{$\begin{array}{l}\text { SENS classes } \\
\text { Groups of CIQUAL foods }\end{array}$} & \multirow{2}{*}{$\begin{array}{l}\text { All } \\
N\end{array}$} & \multicolumn{2}{|c|}{ Class 1} & \multicolumn{2}{|c|}{ Class 2} & \multicolumn{2}{|c|}{ Class 3} & \multicolumn{2}{|c|}{ Class 4} \\
\hline & & $(\%)$ & $N$ & $(\%)$ & $N$ & $(\%)$ & $N$ & $(\%)$ & $N$ \\
\hline All & 1065 & 30.4 & 323 & 18.3 & 196 & 26.0 & 277 & 25.3 & 269 \\
\hline \multicolumn{10}{|c|}{ Covering four classes ( $n=10$ groups) } \\
\hline Meats & 117 & 29.1 & 34 & 15.4 & 18 & 23.1 & 27 & 32.5 & 38 \\
\hline Fish & 90 & 68.9 & 62 & 14.4 & 13 & 13.3 & 12 & 3.3 & 3 \\
\hline Sandwiches and salty pastries & 79 & 1.3 & 1 & 12.7 & 10 & 40.5 & 32 & 45.6 & 36 \\
\hline Mixed dishes and broth & 68 & 23.5 & 16 & 42.7 & 29 & 22.1 & 15 & 11.8 & 8 \\
\hline Unrefined starches & 35 & 48.6 & 17 & 40.0 & 14 & 8.6 & 3 & 2.9 & 1 \\
\hline Spices and sauces & 24 & 12.5 & 3 & 8.3 & 2 & 29.2 & 7 & 50.0 & 12 \\
\hline Dairy desserts & 23 & 8.7 & 2 & 4.4 & 1 & 73.9 & 17 & 13.0 & 3 \\
\hline Breakfast cereals & 22 & 9.1 & 2 & 9.1 & 2 & 40.9 & 9 & 40.9 & 9 \\
\hline Dry fruits and seeds & 19 & 5.3 & 1 & 31.6 & 6 & 36.8 & 7 & 26.3 & 5 \\
\hline Refined starches & 17 & 17.7 & 3 & 47.1 & 8 & 29.4 & 5 & 5.9 & 1 \\
\hline \multicolumn{10}{|c|}{ Covering three classes ( $n=9$ groups) } \\
\hline Vegetables, crudités and soup & 103 & 93.2 & 96 & 5.8 & 6 & 1.0 & 1 & - & - \\
\hline Cheese & 98 & - & - & 13.3 & 13 & 75.5 & 74 & 11.2 & 11 \\
\hline Biscuits and sweets & 63 & 1.59 & 1 & - & - & 1.6 & 1 & 96.8 & 61 \\
\hline Fruits (fresh and processed) & 51 & 76.5 & 39 & 15.7 & 8 & 7.8 & 4 & - & - \\
\hline Yoghurt & 43 & 51.2 & 22 & 20.9 & 9 & 27.9 & 12 & - & - \\
\hline Sweetened beverages & 27 & - & - & 18.5 & 5 & 29.6 & 8 & 51.9 & 14 \\
\hline Vegetable fat & 25 & - & - & 44.0 & 11 & 44.0 & 11 & 12.0 & 3 \\
\hline Milk & 18 & 72.2 & 13 & 16.7 & 3 & 11.1 & 2 & - & - \\
\hline Eggs & 13 & 38.5 & 5 & 23.1 & 3 & 38.5 & 5 & - & - \\
\hline \multicolumn{10}{|l|}{ Covering two classes ( $n=4$ groups) } \\
\hline Cake, tarts and Viennese pastries & 67 & - & - & - & - & 14.9 & 10 & 85.1 & 57 \\
\hline Plain fruit juices & 21 & - & - & 85.7 & 18 & 14.3 & 3 & - & - \\
\hline Animal fat & 19 & - & - & - & - & 63.2 & 12 & 36.8 & 7 \\
\hline Tofu and soya-based products & 5 & 40 & 2 & 60.0 & 3 & - & - & - & - \\
\hline \multicolumn{10}{|c|}{ Covering one class only ( $n=3$ groups) } \\
\hline Tea, coffee & 7 & - & - & 100 & 7 & - & - & - & - \\
\hline Water & 5 & 100 & 5 & - & - & - & - & - & - \\
\hline Diet-sweetened beverages & 6 & - & - & 100 & 6 & - & - & - & - \\
\hline
\end{tabular}

Food groups are ranked by decreasing number of classes covered

between Class 2 and Class 3 such as 'vegetable fat', 'refined starches' and 'dry fruits and seeds'. The 'meats' group was fairly evenly distributed among all four SENS classes, ranging from $15 \%$ in Class 2 to $33 \%$ in Class 4.

The 'cheese' group counted high proportions of Class 3 foods; 'sandwiches and salty pastries' and 'breakfast cereals' were evenly distributed across Class 3 and Class 4; and about half of 'sweetened beverages' were classified in Class 4. A very high proportion of discretionary foods (i.e. $85 \%$ of 'cakes, tarts and viennese pastries', $97 \%$ of 'biscuits and sweets') were classified in Class 4 (Table 5).

\section{Distribution of food ED values by SENS classes}

Figure 2 charts the distribution of the energy density (ED, panel a) and the nutrient density score (NDS, panel b) of CIQUAL foods by SENS classes. Class-1 foods had a low ED (3rd quartile <200 kcal/100 g) and a high NDS (1st quartile $=7.6 \%$ adequacy $/ 100 \mathrm{kcal})$. Median ED increased significantly and median NDS decreased significantly with increasing SENS classes $(71 \mathrm{kcal} / 100 \mathrm{~g}$ and $12.4 \%$ adequacy $/ 100 \mathrm{kcal}$ in Class $1 ; 123 \mathrm{kcal} / 100 \mathrm{~g}$ and $5.9 \%$ adequacy/100 Kcal in Class 2; $250 \mathrm{kcal} / 100 \mathrm{~g}$ and $4.4 \%$ adequacy $/ 100 \mathrm{kcal}$ in Class $3 ; 355 \mathrm{kcal} / 100 \mathrm{~g}$ and $2.7 \%$ adequacy/100 kcal in Class 4). For ED, the inter-quartile 
range increased from Class 1 to Class 4, but with wide overlaps, especially between Class 3 and Class 4 . Betweenclass overlaps were less marked for NDS than for ED.

\section{Discussion}

The SENS algorithm is a new nutrient profiling system developed for simplified labelling in Europe. It classifies foods using non-compensating scores, meaning that a low amount of disqualifying nutrients is not sufficient to get a favourable profile, as a high nutrient density is also required. The SENS algorithm has been adapted and simplified from the SAIN,LIM system by integrating specificities of food categories, reducing the number of nutrients, ranking the four classes, and introducing EU reference intakes. The rationale for using the SAIN,LIM as a basis for SENS was that the SAIN,LIM was endorsed by the French authorities in 2008 and was designed from the outset with future adaptability in mind, i.e. with possibilities for updating nutritional values and integrating category-specific nutrients [17].

The 2010 WHO recommendations on adopting a stepwise process for the development of a nutrient profiling model [2] were carefully followed here to develop the SENS algorithm. European guidelines were also fully integrated as the SENS algorithm uses validated reference values (EU-RIs), as required under EU Regulation (EC $1169 / 2011$ ), which is not the case for other systems, such as the FSA-Ofcom [4].

As category specific systems with a limited numbers of categories are deemed to be preferable when designing nutrient profile [28], eight food categories and subcategories were identified that are close to those considered in nutrient profiling systems proposed by the EC [29] and the WHO Regional Office for Europe [30]. In addition, although SENS takes into account the specificities of food categories through the use of category-specific

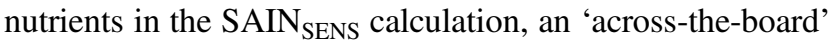
approach is maintained in the mathematical format of the score which always reflects a mean percentage of nutritional adequacy. This is consistent with the EFSA preference for a mixed system to overcome the main disadvantages of both 'across-the-board' and 'category-based' schemes [18].

WHO states that one simple method to validate a nutrient profile system is to test whether classifications using nutrient profiling are in line with food-based dietary guidelines [2]. Our results show that the SENS algorithm assigned FV mostly in Class 1 and discretionary foods mostly-but not exclusively-in Class 4. Most food groups were distributed in three or four SENS classes. A strength of the SENS algorithm is its capacity to discriminate foods both between and within food groups. Fish ranked higher than meat ( $70 \%$ vs $30 \%$ in Class 1). Unrefined starches ranked better than refined cereals (50\% vs $15 \%$ in Class 1$)$, milk and yoghurt (mostly Classes 1 and 2) ranked better than cheese or dairy desserts (both mostly Class 3), vegetable fats (mostly Classes 2 and 3) ranked better than animal fats (Classes 3 and 4). Our results are therefore fully in line with the core messages in Europe to consume adequate amounts of grains, vegetables and fruits with moderate intake of fats, sugars, meats, caloric beverages and salt [31].

The association of a nutrient profiling system with ED can be considered as another validation element of this model [32]. Nutrient profiling systems are expected to favour low-ED foods over high-ED foods, which the SENS algorithm clearly does. But nutrient profiling systems are also expected to go beyond classifying foods merely based on their ED [33]. Accordingly, the SENS classification showed some between-class overlaps in ED values, especially between Class 3 and Class 4 and to a lesser extent between Class 2 and Class 3. Moreover, SENS classes were inversely associated with the NDS, showing that the algorithm adequately ranks foods according to their nutrient density. In contrast, the original FSA-Ofcom was shown to be highly correlated to the energy density of foods yet only loosely correlated to nutrient density scores [32].

There are limitations to address. The food database used for this study was too generic to fully demonstrate the precise discriminative capacity of the SENS algorithm within a narrow range of food products. However, during the iterative development process, the classification was cotested on both the CIQUAL database of generic food products and on a database of real food products $(n=1737)$, and it was the resulting classifications at each step of the process that helped forge the final SENS algorithm [16]. For instance, while generic cheeses mainly scored in Class 3, 'real' cheese products were well scattered from Class 2 to Class 4 (data not shown). Another limitation is that some edge effects are likely to remain. However, because SENS is a multicriteria system, modest changes, such as modifying the content of a single nutrient, should not change the classification of a food, except for products already extremely close to an edge. In addition, specific calculation rules (e.g. maximum amounts for qualifying nutrients) were established in order to prevent undue fortification practices aimed at climbing one class. More generally, in the absence of gold standard for defining the nutritional quality of individual foods [2], classification's pitfall is the main limitation affecting all nutrient profiling models. Classifications may be more prone to debate for some foods than others. For instance, within beverages, it has presently been decided to give a specific position to plain water, which is the only beverage eligible to Class 1 . This decision came from the examination of food-based dietary guidelines in EU countries, a majority of which providing 
recommendation for daily consumption of plain water [31]. However, other non-caloric beverages, especially tea and coffee could also join this exception if needed, as they are often included in the fluid group in food-based dietary guidelines [31].

Regarding fruit juices, the decision was grounded on the fact that plain fruit juices contain beneficial nutrients, which is not the case of other soft drinks. However, SENS classification of fruit juices could be questioned, especially because the link between fruit juice intake and obesity development is controversial $[34,35]$.

Compared to other systems $[8,4]$, the SENS algorithm, just as the SAIN,LIM from which it originates, has the advantage of integrating official nutritional recommendations in the calculation; taking into account nutritional density of foods (represented by the SAIN component); and using easily understandable scores (\% of adequacy for the $\mathrm{SAIN}_{\mathrm{SENS}}$ and $\%$ of excess for the $\mathrm{LIM}_{\mathrm{SENS}}$ ). Nevertheless, the main challenge to operational implementation of the SENS algorithm, as well as other systems, is the risk of missing data on some products. The applicability of any systems remains bounded by data availability. Components from mandatory nutrition declaration set out in the EU Regulation (EC 1169/2011) are generally not sufficient to calculate the scores. Thus, information on FV and fibres, although not mandatory for labelling, is required by both FSA-Ofcom and SENS systems, but definitions of what is considered FV differ between systems (e.g. FSA-Ofcom counts nuts and pulses in FV, SENS does not because their protein and fibre contents are sufficient to ensure them a favourable ranking with the SENS algorithm). Regarding fibres, no assay method is officially recommended: products evaluated with the NSP method, which only measures non starch polysaccharides, would be somewhat penalised compared to those evaluated with AOAC, which also measures other types of fibres.

Supplemental information is specifically needed for SENS regarding free sugars, calcium, vitamin C, MUFA and ALA, which may be viewed as a limitation because the system is too demanding. However, it is noteworthy that the nutrients included in the SENS algorithm are exactly the same as those previously identified by US researchers using a totally different approach applied to a different data set [36]. Applying a statistical approach based on correlations between nutrients intakes and an overall index of dietary quality (the Healthy Eating Index) on data from the NHANES survey, Arsenault et al. [36] also identified protein, fibre, calcium, unsaturated fats, vitamin $\mathrm{C}$, saturated fats, sodium and added sugars as relevant nutrients to describe the nutrient profile of a given food, suggesting that these choices are robust and could be valid elsewhere.
These nutrients thus appear needed to adequately describe the nutritional quality of food products, and this may provide reformulations opportunities, aiming at increasing nutrient density and avoiding the replacement of nutrientdense ingredients by empty ingredients. In the same US study, unsaturated fat was also identified as a key marker dietary quality [36]. Owing to the recognised importance of replacing saturated fats with unsaturated fats (especially polyunsaturated fatty acids) [37], including polyunsaturated fats for solid foods in our score may be desirable with a view to improving the SENS algorithm. Thus far, information on polyunsaturated fats content of food products is not easily accessible.

Integrating free sugars in the calculation of the LIM ${ }_{\text {SENS }}$ could be considered a limitation, as free sugars are not label-mandatory in Europe, and are not displayed in European food composition tables. This decision was taken to be in line with recommendations from public health authorities worldwide, which are increasingly referring to free or added sugars rather than total sugars. Indeed, WHO recommends cutting free sugars intake to less than $10 \%$ of total energy intake [22], and the UK Scientific Advisory Committee on Nutrition (SACN) recently adopted a $5 \%$ maximum level of energy from free sugars [38]. However, other authorities, for instance in the US [39], and Belgium [40], recently endorsed 'added' sugars rather than 'free' sugars (which includes sugars from fruit juices, honey and syrups, in addition to 'added' sugars), and questioned free sugars as the basis on which dietary recommendations should be derived. Should the final consensus be on 'added', rather than on 'free' sugars, the SENS algorithm could easily be updated to consider 'added' sugars, with little anticipated changes on product classification vs considering 'free' sugars. Distinguishing between added and total sugars remains nevertheless important, even if such a distinction has no clear physiological justifications. As a matter of facts, the SENS is also intended to guide stakeholders towards improvements of the nutritional quality of their products, and pointing on sugars which can be cut out during product formulation is consistent with this objective.

The SENS has been developed to enable simplified nutritional labelling of food products. Graphical representations of the result (i.e. the position of the product into one of the four classes) are currently being worked out and tested for understanding. The consumer will thus not be aware of the 'back-office' of the system, unless he wants to, which could be possible through web site. The relative complexity of the system is thus not an issue from the consumer's point of view. Implementation of the system will however require nutritional knowledge and training of food manufacturers. 


\section{Conclusion}

The SENS algorithm preserves the strengths of the initial SAIN,LIM system while making it more operational, taking into account specificities of food categories, complying with EU-RIs, and extending its use for simplified nutrition labelling. SENS accurately classifies foods between and within food categories, suggesting that it could be useful in the context of simplified nutrition labelling in Europe. Finally, we should not forget that food labelling, even if based on a validated nutrient profiling system, could improve food choices only if integrated into a comprehensive health prevention strategy promoting food diversity and consumption of moderate portions.

Acknowledgements Several food companies and sectors have financially contributed, as stakeholders to this project: Atla, Auchan Retail, Boissons rafraîchissantes de France, Carrefour, Casino, Findus, Fleury Michon, Marie Sablé, Monoprix, Système U, Unijus. This contribution reflects their involvement for the improvement of the provision of food information to consumers and should not be considered as a support to the system described in this publication.

\section{Compliance with ethical standards}

Conflict of interest N.D. is an employee of the French National Institute for Agriculture Research (INRA). N.D. did not receive personal fees from food retailers and industries and has no conflict of interest. V.B. is employee of VAB-Nutrition. J.S. and M.M. are employees of MS-Nutrition. VAB-Nutrition and MS-Nutrition have received fees from the funding bodies for their participation in this work and have been receiving financial support from some of them for scientific projects unrelated to the SENS.

Open Access This article is licensed under a Creative Commons Attribution-NonCommercial-NoDerivatives 4.0 International License, which permits any non-commercial use, sharing, distribution and reproduction in any medium or format, as long as you give appropriate credit to the original author(s) and the source, and provide a link to the Creative Commons license. You do not have permission under this license to share adapted material derived from this article or parts of it. The images or other third party material in this article are included in the article's Creative Commons license, unless indicated otherwise in a credit line to the material. If material is not included in the article's Creative Commons license and your intended use is not permitted by statutory regulation or exceeds the permitted use, you will need to obtain permission directly from the copyright holder. To view a copy of this license, visit http://creativecommons.org/licenses/by-nc-nd/4.0/.

\section{References}

1. The European Parliament and the Council of the European Union. Regulation (EU) No 1169/2011 of the European Parliament and of the Council of 25 October 2011 on the provision of food information to consumers. Official Journal of the European Union. 2011;304:18-63.

2. WHO/IASO. Nutrient profiling: report of a WHO/IASO technical meeting. London: World Health Organization; 2010. p. 28.

3. Van Kleef E, Dagevos H. The growing role of front-of-pack nutrition profile labeling: a consumer perspective on key issues and controversies. Crit Rev Food Sci Nutr. 2015;55:291-303. http://www.tandfonline.com/doi/abs/10.1080/10408398.2011. 653018. Accessed 5 Oct 2017.

4. Department of Health. Nutrient profiling technical guidance. London, UK: Department of Health; 2011.

5. Ni Mhurchu C, Brown R, Jiang Y, Eyles H, Dunford E, Neal B. Nutrient profile of 23596 packaged supermarket foods and nonalcoholic beverages in Australia and New Zealand. Public Health Nutr. 2016;19:401-8.

6. Swedish National Food Agency. The Keyhole symbol. 2015. https://www.livsmedelsverketse/en/food-and-content/labelling/ nyckelhalet. Accessed 19 Aug 2017.

7. Heart symbol. A better choice. http://www.sydanmerkki.fi/en/. Accessed 01 Sept 2017.

8. Roodenburg AJC, Popkin BM, Seidell JC. Development of international criteria for a front of package food labelling system: the International Choices Programme. Eur $\mathrm{J}$ Clin Nutr. 2011;65:1190-200.

9. UK Department of Health. Guide to creating a front of pack (FoP) nutrition label for pre-packed products sold through retail outlets. 2013. https://www.gov.uk/government/publications/front-of-packnutrition-labelling-guidance [Internet].

10. Australian Government. Guide for industry to the Health Star Rating Calculator (HSRC). http://healthstarrating.gov.au/internet/ healthstarrating/publishing.nsf/Content/About-health-stars. Accessed 5 Oct 2017.

11. Julia C, Ducrot P, Péneau S, Deschamps V, Méjean C, Fézeu L, et al. Discriminating nutritional quality of foods using the 5-colour nutrition label in the French food market: consistency with nutritional recommendations. Nutr J. 2015;14:100.

12. Institute of Medicine. Front-of-package nutrition rating systems and symbols: promoting healthierchoices. Washington, DC: The National Academies Press [Internet]. 2012. https://doi.org/10. $17226 / 13221$

13. Darmon N, Vieux F, Maillot M, Volatier JL, Martin A. Nutrient profiles discriminate between foods according to their contribution to nutritionally adequate diets: a validation study using linear programming and the SAIN,LIM system. Am J Clin Nutr. 2009;89:1227-36.

14. The European Parliament and the Council of the European Union. Regulation (EC) No 1924/2006 of the European Parliament and of the Council of 20 December 2006 on nutrition and health claims made on foods. Off J Eur Union. 2006;L 404:9-25.

15. World Health Organization. WHO interventions on diet and physical activity: what works: summary report. Geneva: World Health Organization; 2009.

16. Darmon N, Maillot M, Braesco V, Tafournel E L'Algorithme du Système d'Etiquetage Nutritionnel Simplifié (SENS) Développement, description et validation. 2015.

17. AFSSA. Définition de profils nutritionnels pour l'accès aux allégations nutritionnelles et de santé: propositions et arguments. Paris 2008.

18. EFSA Panel on Dietetic Products Nutrition and Allergies (NDA). The setting of nutrient profiles for foods bearing nutrition and health claims pursuant to article 4 of the regulation (EC) ${ }^{\circ} \mathrm{NO}$ 1924/2006. EFSA J. 2008;644:1-44.

19. Ministère de la Santé. Programme National Nutrition Santé (PNNS). 2001.

20. Drewnowski a, Maillot M, Darmon N. Should nutrient profiles be based on $100 \mathrm{~g}, 100 \mathrm{kcal}$ or serving size? Eur J Clin Nutr. 2009;63:898-904.

21. EFSA Panel on Dietetic Products Nutrition and Allergies (NDA). Scientific Opinion on Dietary Reference Values for carbohydrates and dietary fibre. EFSA J. 2010; 8:1462. 
22. World Health Organization. WHO guideline: sugars intake for adults and children. Geneva: World Health Organization; 2015. p. 49.

23. Vieux F, Perignon M, Gazan R, Darmon N. Dietary changes needed to improve diet sustainability: are they similar across Europe? (under revision). Eur J Clin Nutr. 2017.

24. World Health Organization. Global action plan for the prevention and control of noncommunicable diseases 2013-2020. Geneva: WHO Press; 2013. p. 102.

25. World Cancer Research Fund International. Foods and drinks that promote weight gain. http://www.wcrf.org/int/research-we-fund/ continuous-update-project-cup. Accessed 5 Oct 2017.

26. Louie JCY, Moshtaghian H, Boylan S, Flood VM, Rangan AM, Barclay AW, et al. A systematic methodology to estimate added sugar content of foods. Eur J Clin Nutr. 2015;69:154-61.

27. Darmon N, Darmon M, Maillot M, Drewnowski A. A nutrient density standard for vegetables and fruits: Nutrients per calorie and nutrients per unit cost. J Am Diet Assoc. 2005;105:1881-7.

28. Scarborough P, Arambepola C, Kaur A, Bhatnagar P, Rayner M. Should nutrient profile models be "category specific" or "acrossthe-board"? A comparison of the two systems using diets of British adults. Eur J Clin Nutr. 2010;64:553-60.

29. European Commission. Working document on the setting of nutrient profiles. Brussels: European Commission; 2009.

30. World Health Organization Regional Office for Europe. WHO Regional Office for Europe Nutrient Profile Model. Copenhagen: WHO Regional Office for Europe; 2015.

31. Montagnese C, Santarpia L, Buonifacio M, Nardelli A, Caldara AR, Silvestri E, et al. European food-based dietary guidelines: a comparison and update. Nutrition. 2015;31:908-15.

32. Drewnowski a, Maillot M, Darmon N. Testing nutrient profile models in relation to energy density and energy cost. Eur J Clin Nutr. 2009;63:674-83. http://www.ncbi.nlm.nih.gov/pubmed/ 18285808 [Internet].

33. Drewnowski A, Fulgoni V. Nutrient profiling of foods: creating a nutrient-rich food index. Nutr Rev. 2008;66(1):23-39.
34. Crowe-White K, O’Neil CE, Parrott JS, Benson-Davies S, Droke E, Gutschall M, et al. Impact of $100 \%$ Fruit Juice Consumption on Diet and Weight Status of Children: An Evidence-based Review. Crit Rev Food Sci Nutr. 2016;56:871-84. http://www.tandfonline. com/doi/full/10.1080/10408398.2015.1061475 [Internet] 3 Apr [cited 9 Mar 2017].

35. A review of the evidence to address targeted questions to inform the revision of the Australian Dietary Guidelines [Internet]. Canberra; NHMRC, National Health and Medical Research Council, 2011. https://www.nhmrc.gov.au/_files_nhmrc/file/publications/ n55d_australian_dietary_guidelines_evidence_report.pdf. Accessed 5 Oct 2017.

36. Arsenault JE, Fulgoni VL, Hersey JC, Muth MK. A novel approach to selecting and weighting nutrients for nutrient profiling of foods and diets. J Acad Nutr Diet. 2012;112:1968-75.

37. US Department of Agriculture, US Department of Health and Human Services. Dietary guidelines for Americans, 2010 [Internet]. Washington, DC: US Department of Agriculture, US Department of Health and Human Services; 2010. Available from: https://health.gov/dietaryguidelines/dga2010/dieta ryguidelines2010.pdf.

38. Scientific Advisory Committee on Nutrition (SACN). Carbohydrates and Health. London: TSO; 2015. p. 369.

39. Food and Drug Administration (FDA). Food Labeling: Revision of the Nutrition and Supplement Facts Labels. Fed Regist. 2016;81:33741-999.

40. Conseil Supérieur de la Santé. Recommandations nutritionnelles pour la Belgique - 2016. Bruxelles, 2016.

41. EFSA Panel on Dietetic Products Nutrition and Allergies (NDA). Scientific opinion on dietary reference values for fats, including saturated fatty acids, polyunsaturated fatty acids, monounsaturated fatty acids, trans fatty acids, and cholesterol. EFSA J. 2010;8:1461.

42. Food and Agriculture Organization of the United Nations (FAO). Fats and fatty acids in human nutrition. Report of an expert consultation. FAO Food Nutr Pap. 2010;91:1-166. 